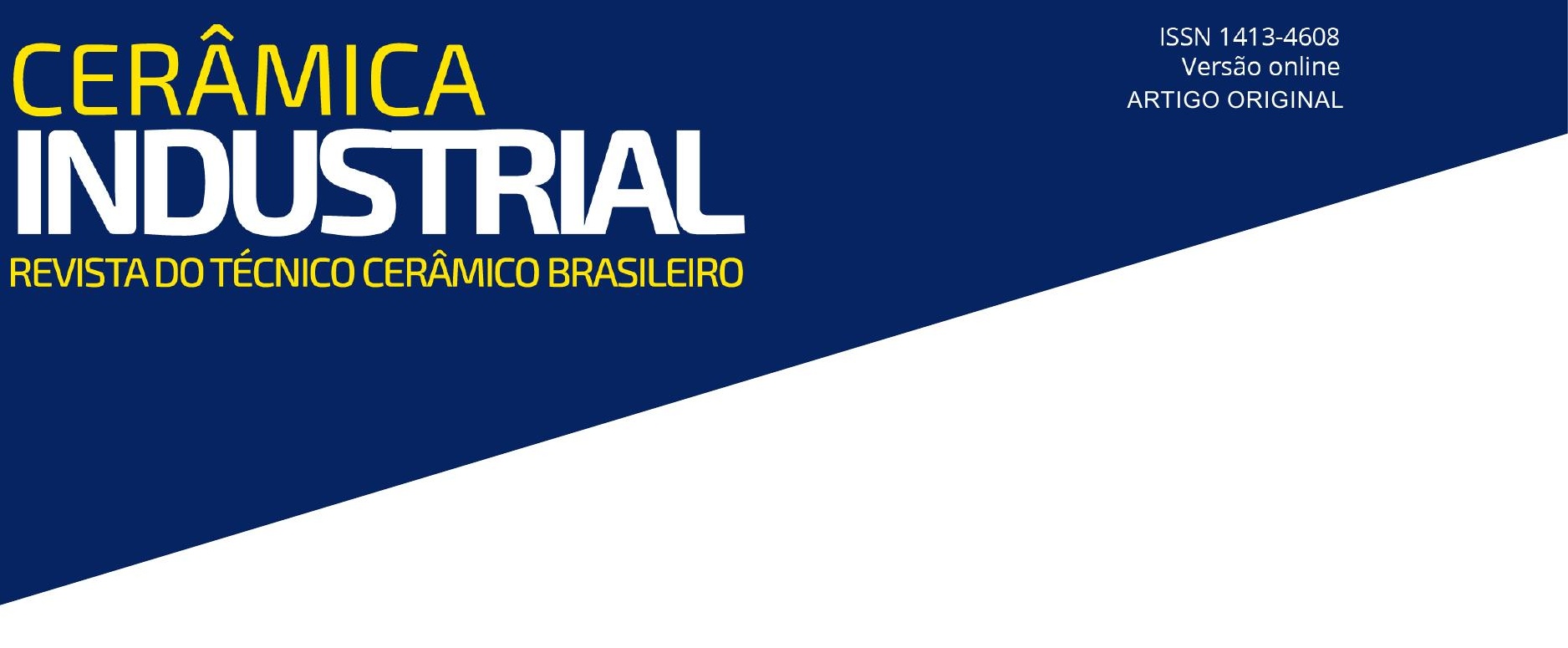

\title{
Comportamento e caracterização do rejeito de Manganês da Serra do Navio/AP em substituição dos agregados no concreto
}

\author{
João Queiroz de Souza Junior'; João Carlos Lisboa de Lima²; Marcelo de Souza Picanço ${ }^{3}$ \\ ${ }^{1}$ Mestre em Processos Construtivos e Saneamento Urbano, Universidade Federal do Pará \\ 2 Doutorando em Engenharia Civil, Universidade Federal do Pará \\ ${ }^{3}$ Professor Doutor, Faculdade de Engenharia Civil, Universidade Federal do Pará, Rua Augusto Corrêa, Número 01. Guamá - \\ Belém - Pará. CEP: 66075-970 \\ e-mail: marcelosp@ufpa.br
}

\section{Resumo}

A utilização de agregados naturais demanda alto consumo de recursos energéticos e logísticos para abastecer as necessidades locais, deste modo, racionalizar o uso de agregados que tenham disponibilidade regional é de suma importância para diminuir custos e gerar práticas sustentáveis. Considerando a necessidade de diminuir os impactos ambientais relacionados à estocagem de rejeitos de manganês na sede de uma mineradora situada no município de Serra do Navio/AP, este artigo tem por objetivo atribuir valor ao rejeito para sua utilização na construção civil como agregado no concreto. Foram moldados uma série de corpos de prova cilíndricos com concreto convencional, seixo e areia, e outro com substituição total pelo rejeito para análise comparativa dos resultados. Foi realizada a caracterização mecânica a partir dos ensaios de resistência à compressão, tração por compressão diametral e módulo de elasticidade, assim como a caracterização química e mineralógica do rejeito através dos ensaios de reação álcali-agregados, fluorescência de raio-x (FRX) e difração de raio-x (DRX). Obteve-se a validação no uso do concreto com rejeito pela sua não reatividade e baixa pozolanicidade, pois apresenta baixos teores de óxido de ferro, silício e alumínio, além de alcançar a resistência mecânica desejável com diferença ao concreto convencional de 18\% para compressão axial, 2\% para compressão diametral e 3\% no módulo de elasticidade, tornando-se plausível o uso pela redução do impacto ambiental regional.

Palavras-chave: rejeito de manganês, agregados, concreto.

\section{INTRODUÇÃo}

Segundo Krausmann et al. (2017), a indústria da construção civil é uma das maiores consumidoras de materiais naturais no mundo com um aumento de aproximadamente 23 vezes desde a década de 1900 até a década de 2010. Krausmann et al. (2009) estima que o consumo de minerais, rochas naturais, agregados e produção de cimento representa $40 \%$ do total da demanda global por recursos naturais, culminando em uma probabilidade de escassez e aumento de preço no valor final de edificações.

O território brasileiro é abundante em diversos minérios, sendo um dos maiores exploradores do mundo, junto à Rússia, Estados Unidos, Canadá, China e Austrália. Isso foi possível em razão de investimentos que 
propiciaram o crescimento dessa atividade nas últimas décadas. Segundo Afonso (2019), o manganês é o quarto metal mais utilizado do mundo, ele existe naturalmente como minério e tem enorme demanda global devido às suas aplicações essenciais para ligas metálicas, sendo usado principalmente na produção de aço, assim como na fabricação de baterias de alta capacidade. Apesar de quase $90 \%$ da produção ser destinada ao setor de siderurgia, suas aplicações incluem ainda a fabricação de fertilizantes, rações de animais e utilização automotiva.

O Brasil possui $10 \%$ das reservas mundiais de manganês, atrás apenas da Ucrânia (24\%), África do Sul (22\%) e Austrália (16\%). Hoje, a maior produção de manganês é realizada na Mina do Azul, da Vale, em Carajás (Parauapebas/PA). Em seguida, a Urucum Mineração, em Corumbá (MS) e a Mineração Buritirama, em Marabá (PA). A BMC (Espigão D’oeste/RO) surge como quarto produtor nacional (Afonso, 2019).

Visando a indústria metalúrgica como grande geradora de resíduos é fundamental a racionalização da cadeia de produção dos rejeitos e do uso na indústria da construção civil com intuito de diminuir impactos ambientais, diminuir custos de produção e armazenamento. Partindo da produção do minério de manganês, a Mina de Serra do Navio no estado do Amapá, que foi a mais duradouro e importante empreendimento produtivo na curta história do estado, produziu durante seu funcionamento de 1957 a 1997 aproximadamente 61 milhões de toneladas minério de manganês e a geração de 26 milhões de toneladas de rejeitos com uma movimentação de 123 milhões de toneladas de material estéril, (Heider \& Amarante, 2018).

No contexto de caracterização do rejeito de manganês, alguns trabalhos como Reis et al. (2010) analisou os produtos granulados da região de Carajás/PA com teor de 52,6\% de manganês em seu peso e diâmetros variando entre $6,3 \mathrm{~mm}$ e $50 \mathrm{~mm}$. Através da difratometria de raios-x (DRX), foram identificadas fases mineralógicas como pirolusita e criptomelana que apresentaram decomposição de seus respectivos óxidos a partir de $600{ }^{\circ} \mathrm{C}$ e a transformação do $\mathrm{Mn}_{2} \mathrm{O}_{3} \mathrm{em} \mathrm{Mn}_{3} \mathrm{O}_{4} \mathrm{em}$ torno de $950^{\circ} \mathrm{C}$ através do ensaio de termogravimétria. Faria et al. (2012) apresentou resultados semelhantes com o rejeito com alto teor de manganês $(47,7 \%)$ da Mina do Azul, com perda de massa em $11 \%$ à $700{ }^{\circ} \mathrm{C}$ e $13,8 \%$ à $1100^{\circ} \mathrm{C}$, com granulometria predominantemente abaixo de $12,5 \mathrm{~mm}$. Salguero et al. (2013) utilizou de forma viável o filler não reativo do rejeito de manganês em substituição do agregado miúdo com propósito de diminuir os impactos ambientais locais, obtendo aumento de resistência à compressão do concreto e melhor trabalhabilidade, sendo atribuído pelos autores o uso em concretos de alto desempenho com objetivo de diminuir o volume de cimento na mistura.

A utilização de resíduos metalúrgicos como agregados é recorrente na literatura. Choi \& Kim (2020) utilizaram a escória de silício-manganês resfriada rapidamente como agregado miúdo em argamassas, o programa experimental consistiu em avaliar as propriedades dos corpos de prova com o agregado dessa escoria resfriado de 3 modos, ar, água, ar e água. Os agregados apresentaram diferentes propriedades físicas, principalmente na massa especifica, vazios e rugosidade da superfície. Concluiu-se que a escória resfriada pelo ar em argamassas apresenta valores de resistência a flexão próximos a argamassa com areia assim como menor absorção de água.

Pimentel et al. (2020) utilizou resíduo de manganês como material suplementar ao cimento Portland que aumentou a resistência à compressão nas idades de 7 e 28 dias com teores de $6 \%, 8 \%$ e $10 \%$ em relação ao concreto convencional. Devido ao efeito filler, o resíduo acelerou a hidratação do C-S-H.

O uso de rejeito de manganês como agregado é escasso na literatura, Viveiros (2017) avaliou a aplicabilidade do rejeito oriundo da Serra de Buritirama/PA como agregado miúdo em substituição da areia em 15\%, 20\%, 25\% e $30 \%$ em concretos. Verificou-se que estatisticamente houve variações significativas nas propriedades mecânicas.

Partindo da escassa literatura relatando a temática deste trabalho, o presente artigo tem por objetivo a caracterização física e química do agregado proveniente do rejeito de Manganês e analisar o comportamento mecânico do concreto com rejeito de Manganês em relação ao convencional e determinar a sua usabilidade.

\section{MATERIAIS E MÉTODOS}

O programa experimental constitui-se em aferir as propriedades mecânicas do concreto com substituição total do agregado graúdo e miúdo por rejeito de manganês (CRM) comparado a um concreto de referência (CR) com agregados convencionais (areia e seixo). Para isso, foi avaliada a constituição química, mineralógica e física do rejeito para validar seu comportamento inerte perante a matriz cimentícia.

\subsection{Materiais utilizados}

Foram adotados na confecção do concreto, cimento Portland composto de pozolana (CP II-Z-32) de acordo cm a NBR 16697 (2018) com massa específica de $3,15 \mathrm{~g} / \mathrm{cm}^{3}$. O agregado miúdo empregado é a areia oriunda dos leitos de rios da região nordeste do estado do Pará, o agregado graúdo é o seixo-rolado de origem silicosa da cidade de Ourém/PA 
e caracterizados segundo a NBR NM 52 (2009), NBR NM (2006), NBR NM 248 (2003) e NBR 7211 (2009) como apresentado na tabela 1 e figura 1 . Aágua utilizada era potável com $\mathrm{pH} 6,0$ e temperatura de $26^{\circ} \mathrm{C}$. Foi utilizado aditivo superplastificante $M C$-PoweFlow $3100^{\circledR}$ da marca $M C$-Bauchemie ${ }^{\circledR}$, com densidade de $1,07 \mathrm{~g} / \mathrm{cm}^{3}$ no concreto com rejeito com objetivo de alcançar abatimento de $160 \pm 10 \mathrm{~mm}$ como no concreto de referência.

Tabela 1 - Caracterização física dos agregados utilizados no CR e CRM.

\begin{tabular}{ccccc} 
Agregado & $\begin{array}{c}\text { Massa específica } \\
\left(\mathbf{g} / \mathbf{c m}^{\mathbf{3}}\right)\end{array}$ & $\begin{array}{c}\text { Massa Unitária } \\
\left(\mathbf{g} / \mathbf{c m}^{\mathbf{3}}\right)\end{array}$ & Módulo de finura & $\begin{array}{c}\text { Diâmetro } \\
\mathbf{m a ́ x i m o}(\mathbf{m m})\end{array}$ \\
Areia & 2,50 & 1,52 & 1,38 & 2,40 \\
Seixo-rolado & 2,99 & 1,49 & 6,25 & 2,40 \\
$\begin{array}{c}\text { Agregado miúdo } \\
\text { (rejeito) }\end{array}$ & 2,56 & 1,52 & 6,10 & 19,0 \\
$\begin{array}{c}\text { Agregado graúdo } \\
\text { (rejeito) }\end{array}$ & 2,99 & 1,47 & 6,60 & 19,0 \\
\hline
\end{tabular}

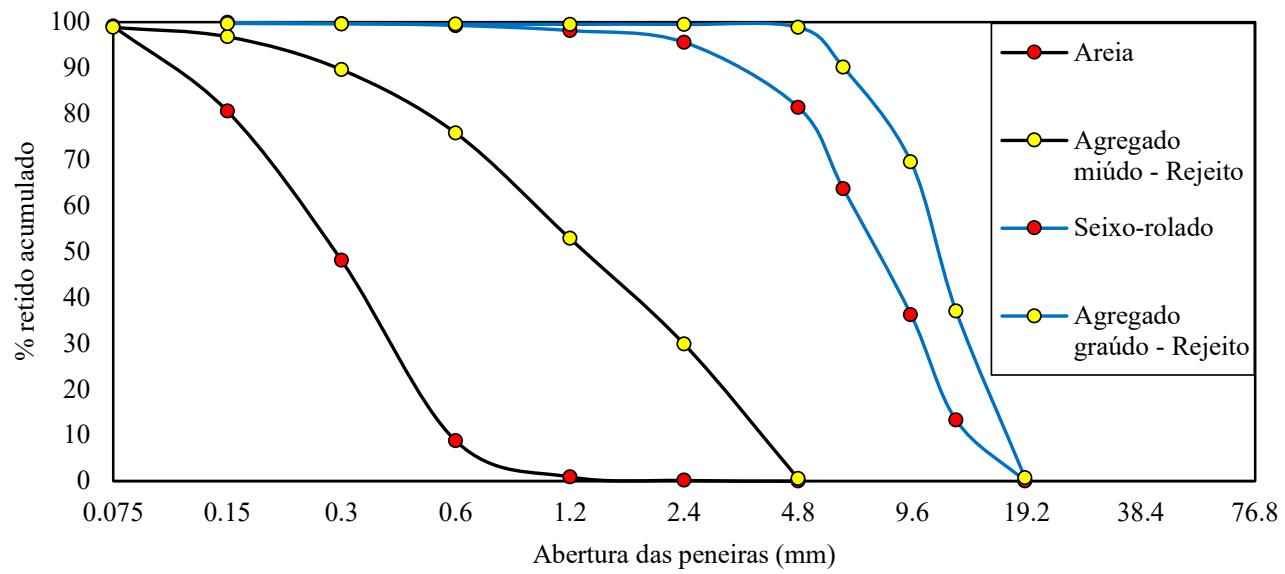

Figura 1 - Curvas granulométricas dos agregados do CR e CRM.

\subsection{Métodos}

\subsubsection{Preparação do rejeito}

O material adotado para essa pesquisa é oriundo da exploração de manganês no estado do Amapá na região da Serra do Navio, onde localizava-se a extração deste minério. A figura 2 ilustra algumas pilhas de rejeito, a figura 3 e figura 4 mostram a localidade da mina da ICOMI, Latitude $0^{\circ} 52{ }^{\prime} 53,49^{\prime \prime} \mathrm{N}$ e Longitude $51^{\circ} 59^{\prime} 42,27^{\prime \prime}$, com pilhas de rejeitos de até $40 \mathrm{~m}$.

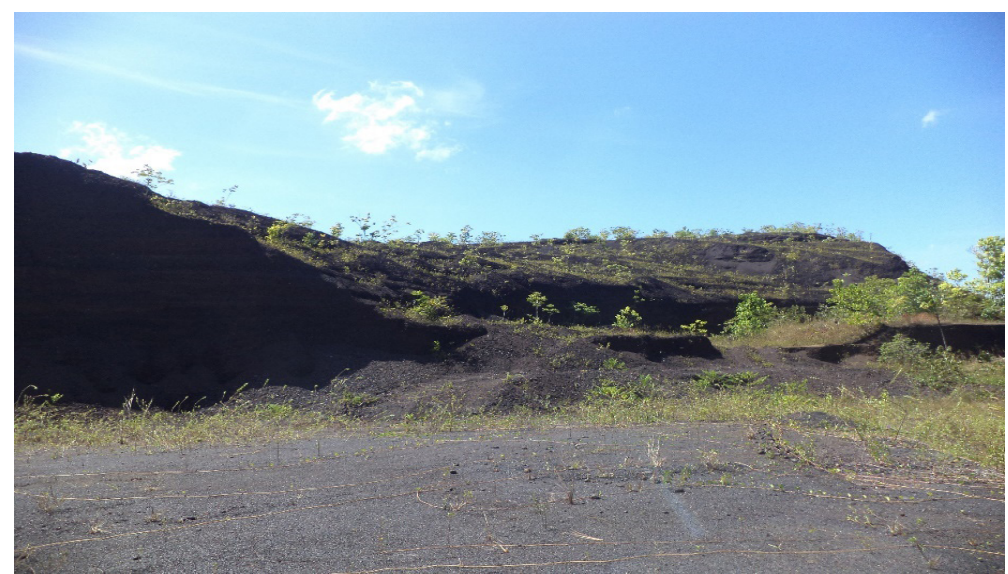

Figura 2 - Montantes de rejeitos de manganês em Serra do Navio/AP 


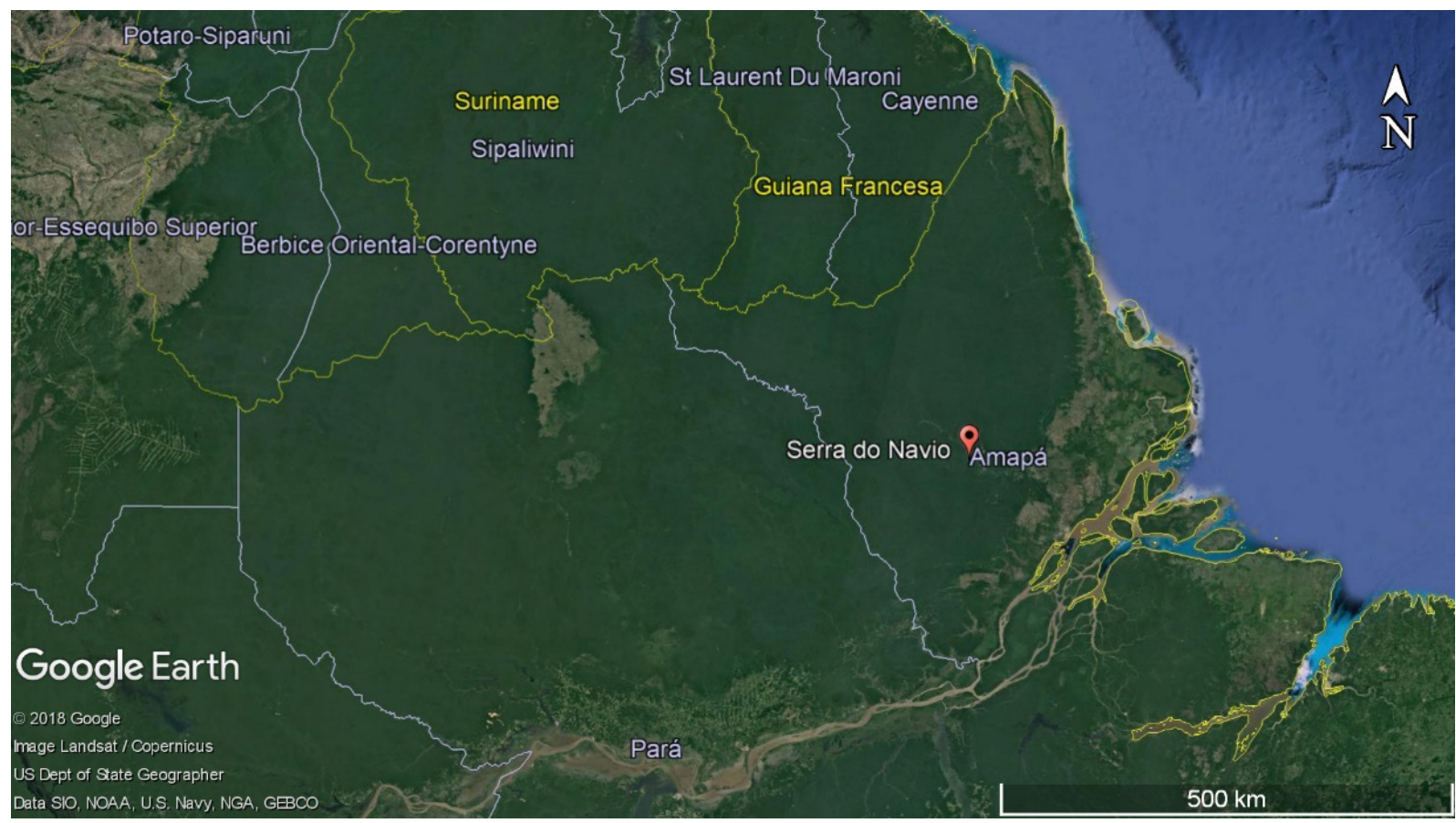

Figura 3 - Localização da Serra do Navio/AP

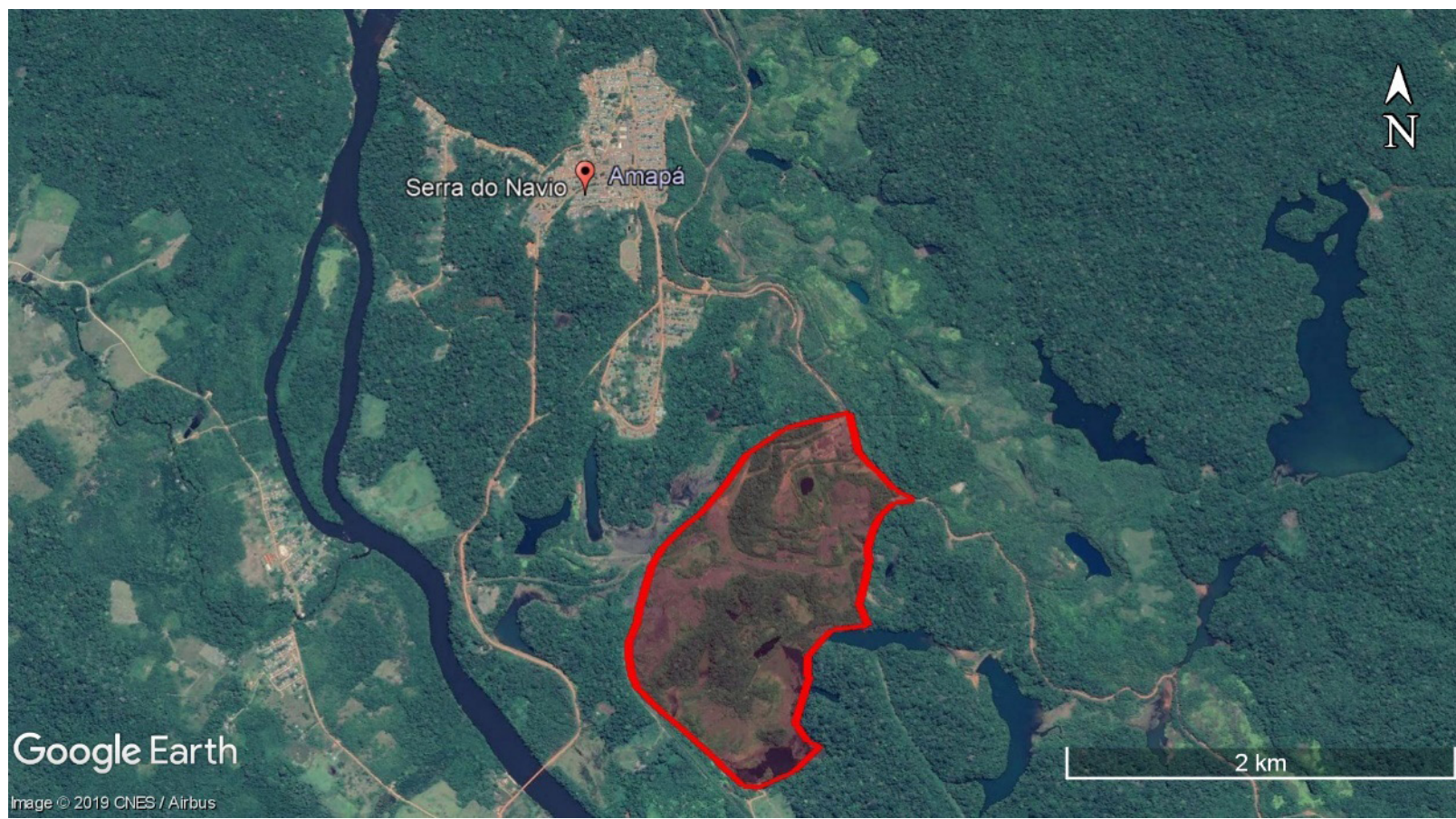

Figura 4 - Delimitação da Mina da ICOMI e a cidade de Serra do Navio/AP

O volume do rejeito de manganês foi retirado segundo as prescrições da NBR 10007 (2004) que tem por objetivo regularizar o tratamento das amostragens de resíduos sólidos e armazenados em recipientes.

O rejeito foi introduzido em estufas a $100^{\circ} \mathrm{C}$ por 48 horas para estabilizar a constância de massa pela retirada de toda umidade intrínseca no material. Como o minério possui variação em sua granulometria visto na figura 5, antes do início da caracterização física, a amostra passou por um britador de mandíbulas Retsch ${ }^{\circledR}$, modelo HSM100 no Laboratório de Engenharia Química da Universidade Federal do Pará, como mostra a figura 6. Em seguida foi peneirada na malha de abertura de $4,75 \mathrm{~mm}$ para separação entre agregado graúdo, para massa retida e miúdo no conteúdo passante. 


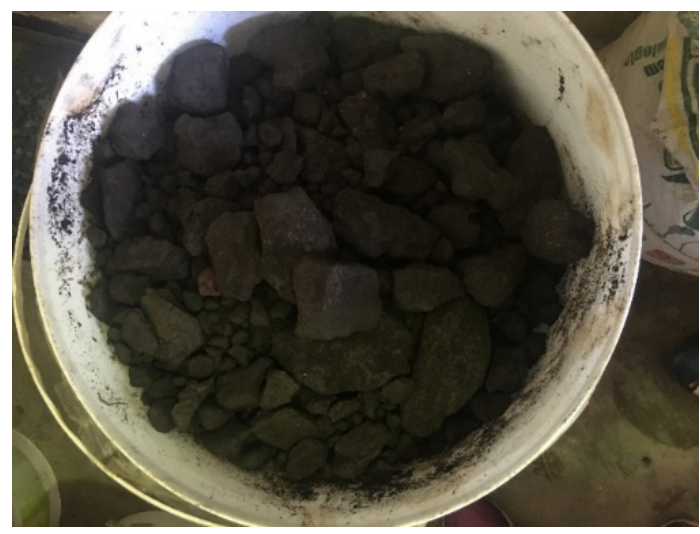

Figura 5 - Variação de granulometria do rejeito de Manganês in natura.

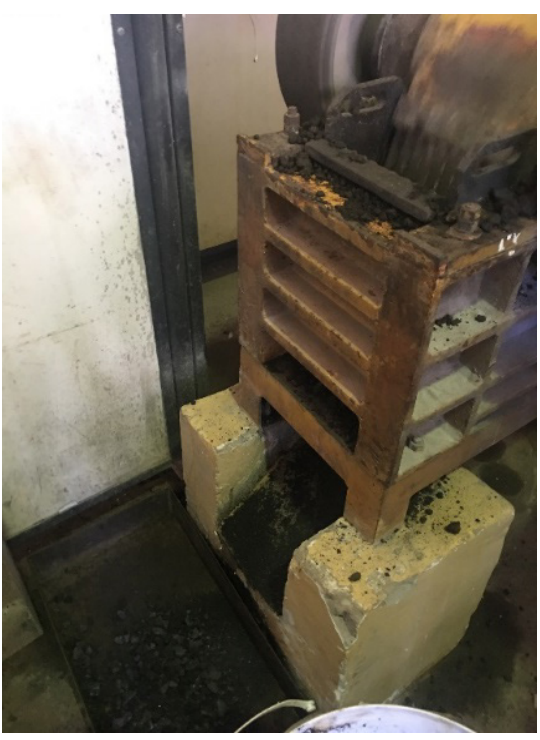

Figura 6 - Britador de mandíbula.

A análise mineralógica do rejeito de manganês foi resultante da difração de raios-X(DRX), pela amostra pulverizada. Os resultados foram realizados em um difratômetro modelo X'PERT PRO MPD (PW 3040/60), da PANalytical, com Goniômetro PW3050/60 ( $\Theta / \Theta)$ e com tubo de raios-X cerâmico de ânodo de $\mathrm{Cu}(\mathrm{K} \alpha 1=1,540598$ Å), modelo PW3373/00, foco fino longo, 2200 W, $60 \mathrm{kv}$ e filtro K $\beta$ de Níquel. O detector utilizado foi do tipo RTMS, X'Celerator. A coleta dos difratogramas foi realizada com passo angular de $0,02^{\circ}$ e o tempo por passo $0.5 \mathrm{~s}$ e intervalo de medida

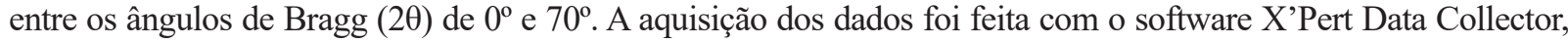
versão 2.1a, e o tratamento dos dados com o software X'PertHighScore versão 2.1b, também da PANalytical.

A interação química entre alguns minerais dos agregados e hidróxidos alcalinos encontrados no cimento em seu estado endurecido, podem criar algumas reações expansivas ao longo de alguns anos nas estruturas de concreto armado, pela formação de um gel sílico-alcalino.

O método para quantificar uma possível reação álcali-agregado foi regido pelo procedimento da norma ASTM C 1260, foram preparados 3 corpos de prova prismáticos segundo a NBR 15577-4 (2018). O Intuito foi confeccionar uma argamassa com o agregado de rejeito de manganês seguindo a dosagem de 990 g do agregado, $440 \mathrm{~g}$ de cimento CP V-ARI e 206,8 $\mathrm{ml}$ de água, adensados em uma argamassadeira.

\subsubsection{Preparação do concreto}

A produção do concreto nesta pesquisa tem como objetivo a viabilidade do rejeito de manganês em obras convencionais em substituição total dos agregados, para isso foi estabelecido um critério mínimo de trabalhabilidade com Slump Test de $160 \pm 10 \mathrm{~mm}$, como visto na figura 7. 


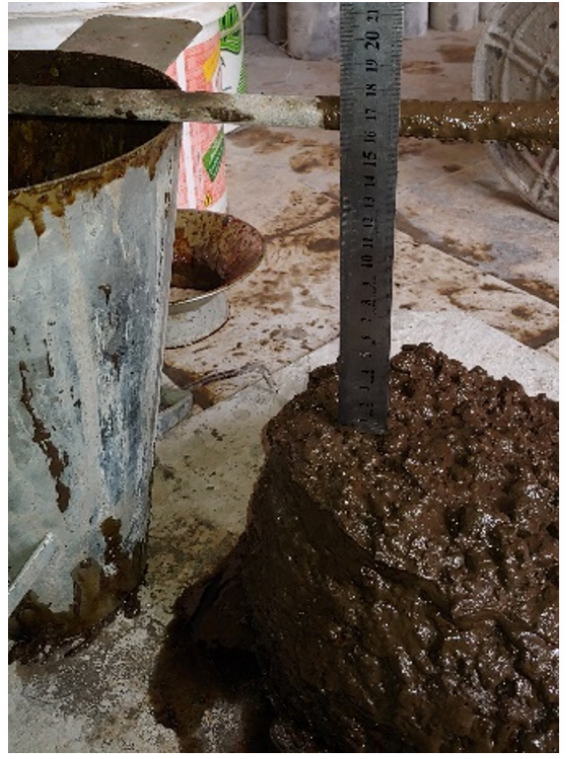

(a)

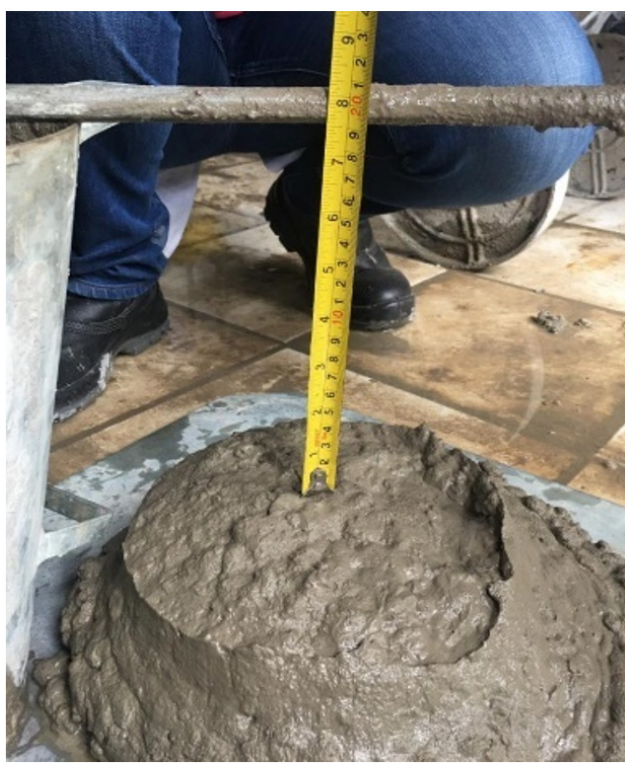

(b)

Figura 7 - Slump Test para o (a) CRM e (b) CR.

O método utilizado para dosagem foi do IPT/EPUSP (HELENE \& TERZIAN, 1992) que consiste em estabelecer uma relação água e cimento correspondente a $20 \mathrm{MPa}$, ou seja, 0,58 com adição de aditivo superplastificante para alcançar o abatimento de tronco de cone estabelecido anteriormente no Slump Test.

O concreto foi produzido com traço unitário de 1:1,82:2,71 e teor de 51\% de argamassa. Houve dois grupos de concretos para comparação de pares, primeiramente com 100\% em substituição dos agregados miúdo e graúdo (CRM), para alcançar o mesmo abatimento do concreto de referência, utilizou-se 2,5\% do peso do aglomerante em aditivo superplastificante. Posteriormente produziu-se o concreto de referência com agregados naturais $(\mathrm{CR})$, porém, sem o uso de aditivos.

Foram confeccionados corpos de prova de $100 \mathrm{~mm}$ de diâmetro e $200 \mathrm{~mm}$ de altura e ensaiados aos 7 dias e 28 dias com as recomendações da NBR 7222 (2011) para a resistência a tração por compressão diametral, o módulo de elasticidade será regido de acordo com a NBR 8522 (2017) e a compressão axial baseada na NBR 7215 (2019).

Tabela 2 - Quantidade de corpos de prova de concreto para ensaios mecânicos.

\begin{tabular}{ccccc} 
Amostra & \multicolumn{4}{c}{ Quantidades } \\
\cline { 2 - 5 } & \% de substituição & $\begin{array}{c}\text { Resistência à } \\
\text { compressão }\end{array}$ & Resistência à tração & $\begin{array}{c}\text { Módulo de } \\
\text { Elasticidade }\end{array}$ \\
CR & 0 & 6 & 6 & 6 \\
CRM & $100 \%$ & 6 & 6 & 6 \\
& Total Parcial & 12 & 12 & 12 \\
& Total & & & 36 \\
\hline
\end{tabular}

\section{RESULTADOS}

A análise quantitativa dos óxidos que compõe o rejeito de manganês foi realizada através fluorescência de raios-X (FRX). O ensaio foi realizado através de um espectrômetro WDS sequencial, modelo Axios Minerals ${ }^{\circledR}$ da PANallytiical ${ }^{\circledR}$, com tubos cerâmicos de raios-X, ânodo de ródio e potência máxima de $2,4 \mathrm{~kW}$. Para preparação da análise utilizou-se pastilhas prensadas à 20 toneladas com $5 \mathrm{~g}$ de amostra do material e 1,5 g de aglomerante (parafina).

Os resultados listados na tabela 3 a seguir foram obtidos a partir de análise quantitativa com curva de calibração a partir de padrões de rocha tabelados da Geostandards. Os valores apresentados estão em porcentagem de peso da amostra. A presença de voláteis (baixo ponto de ebulição), foi avaliada através de técnicas gravimétricas e está representada por LOI, com a decomposição dos hidróxidos. Os dados foram retirados e processados pelo software SuperQ Manager ${ }^{\circledR}$. 
Tabela 3 - Análise química quantitativa do rejeito de Manganês.

\begin{tabular}{ccc}
\hline Componente & Rejeito de Mn \\
\hline $\mathrm{SiO}_{2}$ & \% massa \\
$\mathrm{Al}_{2} \mathrm{O}_{3}$ & 6,85 \\
$\mathrm{Fe}_{2} \mathrm{O}_{3}$ & 22,20 \\
$\mathrm{TiO}_{2}$ & 29,22 \\
$\mathrm{MgO}_{2}$ & 1,06 \\
$\mathrm{P}_{2} \mathrm{O}_{6}$ & 0,37 \\
$\mathrm{~K}_{2} \mathrm{O}$ & 0,12 \\
$\mathrm{CaO}$ & 0,49 \\
$\mathrm{MnO}$ & 0,13 \\
$\mathrm{PF}$ & 24,00 \\
$\mathrm{Total}$ & 15,28 \\
\hline
\end{tabular}

A partir da tabela 3 pode-se inferir que o rejeito não se classifica como adição mineral pozolânica, pois a somatória de $\mathrm{SiO}_{2}+\mathrm{Al}_{2} \mathrm{O}_{3}+\mathrm{Fe}_{2} \mathrm{O}_{3}$ e a perda ao fogo não atendem as exigências químicas da NBR 12653 (ABNT, 2015) que é de no mínimo $70 \%$ da somatória para classes $\mathrm{N}$ e C e $50 \%$ para classe $\mathrm{E}$, assim como o percentual máximo de perda ao fogo é de $10 \%$ para classe $\mathrm{N}$ e $6 \%$ para as classes $\mathrm{C}$ e E, ou seja, o rejeito possui um baixo potencial reativo, por conta disso o material foi utilizado como agregado.

A análise mineralógica do rejeito de manganês foi resultante da difração de raios-X (DRX), pela amostra pulverizada. Os resultados foram realizados em um difratômetro modelo X'PERT PRO MPD (PW 3040/60), da PANalytical, com Goniômetro PW3050/60 ( $\Theta / \Theta)$ e com tubo de raios-X cerâmico de ânodo de $\mathrm{Cu}(\mathrm{K} \alpha 1=1,540598 \AA)$, modelo PW3373/00, foco fino longo, $2200 \mathrm{~W}, 60 \mathrm{kv}$ e filtro K $\beta$ de Níquel. O detector utilizado foi do tipo RTMS, $X^{\prime}$ Celerator. A coleta dos difratogramas foi realizada com passo angular de $0,02^{\circ}$ e o tempo por passo $0.5 \mathrm{~s}$ e intervalo de medida entre os ângulos de Bragg $(2 \theta)$ de $0^{\circ} \mathrm{e} 70^{\circ}$. A aquisição dos dados foi feita com o software X'Pert Data Collector, versão 2.1a, e o tratamento dos dados com o software $\mathrm{X}^{\prime}$ PertHighScore versão 2.1b, também da PANalytical.

O DRX é uma análise que auxilia na compreensão da reatividade do rejeito, o objetivo é identificar as fases cristalinas dos minerais contidos no material, que no caso da figura 8 , apresenta fase predominantemente cristalina com vários picos de difração, assim como os cristais presentes na tabela 4 , deste modo, o material terá dificuldades em se vincular com as reações de hidratação.

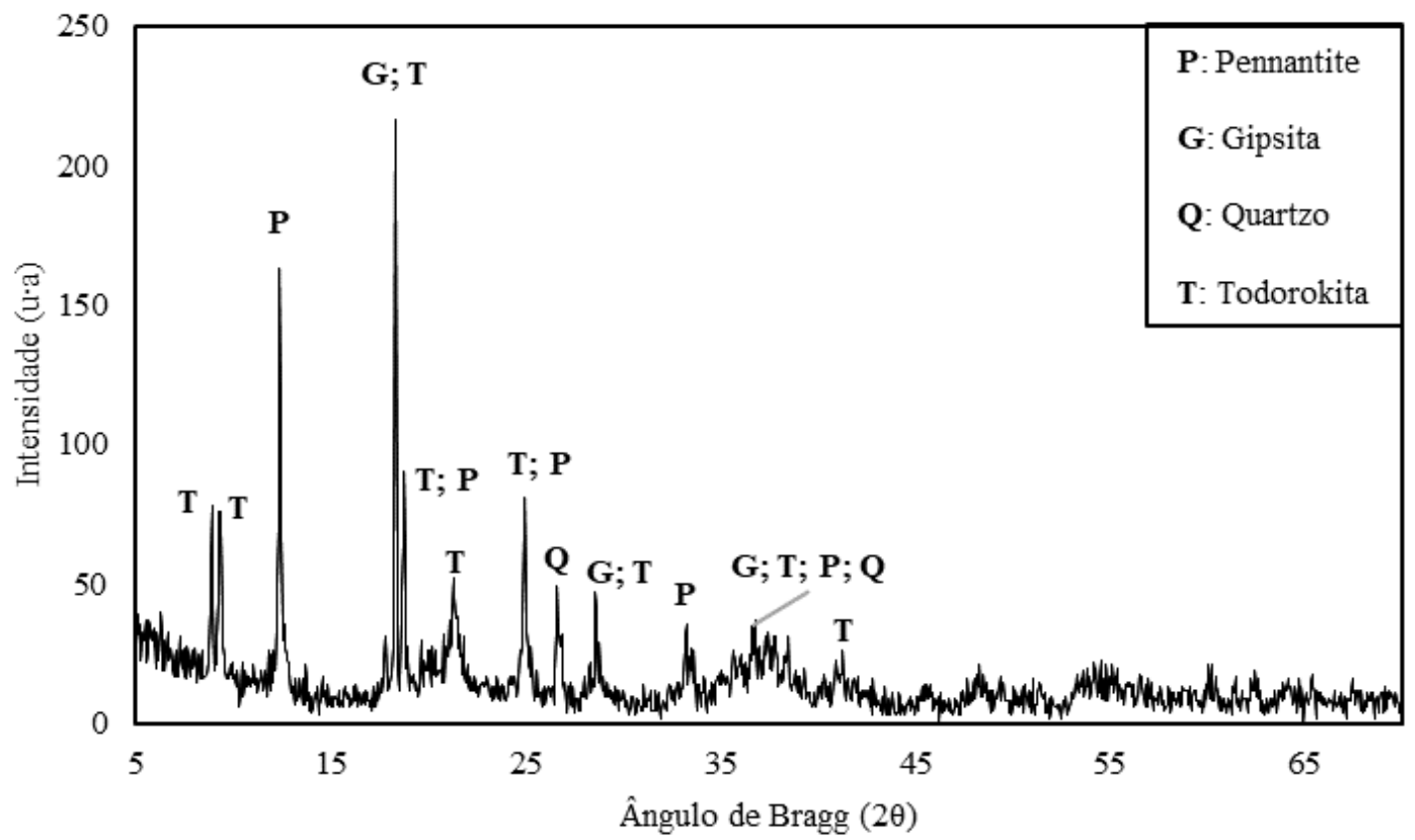

Figura 8 - Diagrama de DRX do rejeito de Manganês. 
Tabela 4 - Fases cristalográficas do rejeito de Manganês.

\begin{tabular}{cc} 
Fase & Ficha cristalográfica \\
Pennantite $(\mathrm{P})$ & $00-029-0884$ \\
$\left(\mathrm{Mn}_{5+2} \mathrm{Al}\right)\left(\mathrm{Si}_{3} \mathrm{Al}\right) \mathrm{O}_{10}(\mathrm{OH})_{8}$ & \\
$\mathrm{Gipsita}(\mathrm{G})$ & $00-007-0324$ \\
$\mathrm{Al}(\mathrm{OH})_{3}$ & $01-087-2096$ \\
Quartzo $(\mathrm{Q})$ & \\
$\mathrm{SiO}_{2}$ & $01-084-1714$ \\
Todorokita $(\mathrm{T})$ & \\
$\mathrm{Mn}_{6} \mathrm{O}_{12}\left(\mathrm{H}_{2} \mathrm{O}\right)_{2}$ & \\
\hline
\end{tabular}

O ensaio para determinar a reação álcali-agregados foi realizado de acordo com a NBR 15577-4 (2018), os corpos de prova (CPs) foram moldados de acordo com a substituição em totalidade do agregado miúdo convencional pelo agregado miúdo de rejeito de manganês, após a moldagem dos CPs, permaneceram em câmara úmida por 24 horas e imersa em uma solução de hidróxido de sódio com medições ao longo de 28 dias.

Nota-se, conforme a figura 9, que o agregado de manganês ficou no limite da reação álcali-agregado, a expansão das amostras não ultrapassou $0,19 \%$, definindo-se como não reativo e favorável para uso.

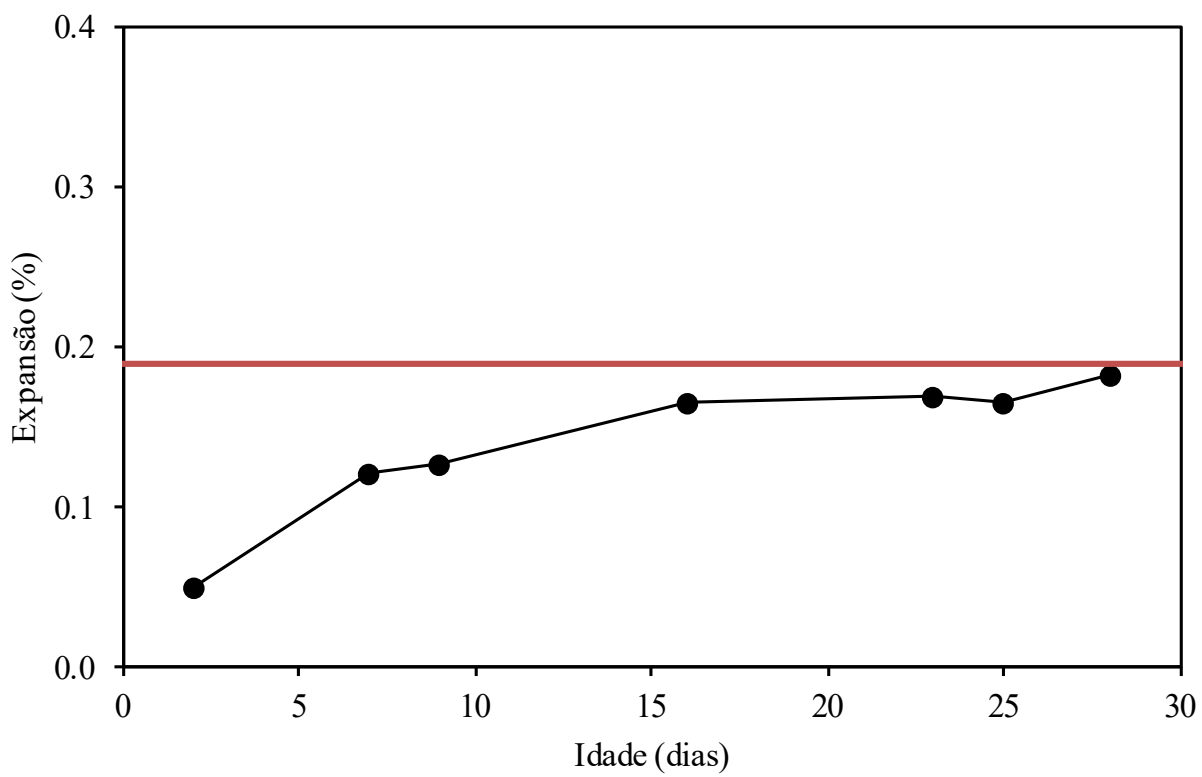

Figura 9 - Expansão do corpo de prova ao longo do tempo.

Partindo dos ensaios químicos e mineralógicos do rejeito, o material mostra-se inerte e improvável de qualquer tipo de reação pozolânica com a pasta de cimento, ou iteração química, desencadeando em patologias a médio e longo prazo. Portando é válido a moldagem de corpos de prova para verificação do comportamento mecânico.

Os ensaios para caracterizar as propriedades mecânicas como resistência à compressão, resistência à compressão diametral e o módulo de elasticidade e seus resultados são apresentados na tabela 5, 6 e 7 .

Tabela 5 - Resistência à compressão do CR e CRM aos 7 e 28 dias.

\begin{tabular}{|c|c|c|c|c|c|c|c|c|}
\hline \multirow[b]{2}{*}{ CPs } & \multicolumn{4}{|c|}{7 dias } & \multicolumn{4}{|c|}{28 dias } \\
\hline & $\begin{array}{l}\text { Resistência } \\
\text { (MPa) }\end{array}$ & $\begin{array}{l}\text { Média } \\
\text { (MPa) }\end{array}$ & $\begin{array}{l}\text { Desvio } \\
\text { padrão }\end{array}$ & $\begin{array}{l}\text { Coeficiente } \\
\text { de variação }\end{array}$ & $\begin{array}{l}\text { Resistência } \\
\text { (MPa) }\end{array}$ & $\begin{array}{l}\text { Média } \\
\text { (MPa) }\end{array}$ & $\begin{array}{l}\text { Desvio } \\
\text { padrão }\end{array}$ & $\begin{array}{l}\text { Coeficiente } \\
\text { de variação }\end{array}$ \\
\hline \multirow{3}{*}{ CR } & 11,68 & & & & 17,44 & & & \\
\hline & 13,06 & 12,01 & 0,93 & 0,08 & 18,40 & 17,36 & 1,09 & 0,06 \\
\hline & 11,29 & & & & 16,23 & & & \\
\hline \multirow{3}{*}{ CRM } & 14,79 & & & & 14,91 & & & \\
\hline & 10,62 & 12,15 & 2,29 & 0,19 & 16,43 & 14,68 & 1,88 & 0,13 \\
\hline & 11,04 & & & & 12,68 & & & \\
\hline
\end{tabular}


Tabela 6 - Resistência à tração por compressão diametral do CR e CRM aos 7 e 28 dias.

\begin{tabular}{|c|c|c|c|c|c|c|c|c|}
\hline \multirow[b]{2}{*}{ CPs } & \multicolumn{4}{|c|}{7 dias } & \multicolumn{4}{|c|}{28 dias } \\
\hline & $\begin{array}{l}\text { Resistência } \\
\text { (MPa) }\end{array}$ & $\begin{array}{l}\text { Média } \\
\text { (MPa) }\end{array}$ & $\begin{array}{l}\text { Desvio } \\
\text { padrão }\end{array}$ & $\begin{array}{l}\text { Coeficiente } \\
\text { de variação }\end{array}$ & $\begin{array}{c}\text { Resistência } \\
\text { (MPa) }\end{array}$ & $\begin{array}{l}\text { Média } \\
\text { (MPa) }\end{array}$ & $\begin{array}{l}\text { Desvio } \\
\text { padrão }\end{array}$ & $\begin{array}{l}\text { Coeficiente } \\
\text { de variação }\end{array}$ \\
\hline \multirow{3}{*}{$\mathrm{CR}$} & 1,60 & & & & 2,02 & & & \\
\hline & 1,72 & 1,63 & 0,08 & 0,05 & 2,09 & 2,01 & 0,08 & 0,04 \\
\hline & 1,56 & & & & 1,92 & & & \\
\hline \multirow{3}{*}{ CRM } & 1,99 & & & & 1,99 & & & \\
\hline & 1,59 & 1,74 & 0,22 & 0,13 & 2,13 & 1,97 & 0,17 & 0,09 \\
\hline & 1,63 & & & & 1,79 & & & \\
\hline
\end{tabular}

Tabela 7 - Módulo de elasticidade do CR e CRM aos 7 e 28 dias.

\begin{tabular}{|c|c|c|c|c|c|c|c|c|}
\hline \multirow[b]{2}{*}{ CPs } & \multicolumn{3}{|c|}{7 dias } & \multirow{2}{*}{$\begin{array}{l}\text { Coeficiente } \\
\text { de variação }\end{array}$} & \multicolumn{3}{|c|}{28 dias } & \multirow{2}{*}{$\begin{array}{l}\text { Coeficiente } \\
\text { de variação }\end{array}$} \\
\hline & $\begin{array}{l}\text { Resistência } \\
\text { (GPa) }\end{array}$ & $\begin{array}{l}\text { Média } \\
\text { (GPa) }\end{array}$ & $\begin{array}{l}\text { Desvio } \\
\text { padrão }\end{array}$ & & $\begin{array}{l}\text { Resistência } \\
\text { (GPa) }\end{array}$ & $\begin{array}{l}\text { Média } \\
\text { (GPa) }\end{array}$ & $\begin{array}{l}\text { Desvio } \\
\text { padrão }\end{array}$ & \\
\hline \multirow{3}{*}{$\mathrm{CR}$} & 19,14 & & & & 23,39 & & & \\
\hline & 20,24 & 19,40 & 0,75 & 0,04 & 24,02 & 23,32 & 0,73 & 0,03 \\
\hline & 18,82 & & & & 22,56 & & & \\
\hline \multirow{3}{*}{ CRM } & 22,31 & & & & 24,32 & & & \\
\hline & 18,90 & 20,16 & 1,87 & 0,09 & 25,54 & 24,10 & 1,56 & 0,06 \\
\hline & 19,27 & & & & 22,43 & & & \\
\hline
\end{tabular}

A partir dos resultados experimentais, é notável a compatibilização da resistência à compressão do CRM aos 7 dias, porém o desvio padrão torna-se maior pela dificuldade de adensamento do agregado miúdo do rejeito, ocasionando alguns pequenos ouriços, que provavelmente desencadearam em zonas de fragilidade, esse detalhe é observado em idades mais avançadas como em 28 dias, que o CRM fica com uma resistência $18 \%$ menor em relação a CR. Quando se avalia a resistência à tração por compressão diametral, observa-se a menor tensão última para o CRM. O módulo de elasticidade para CRM foi maior provavelmente pela diferença granulométrica dos agregados em relação a CR e diferente massa específica dos agregados.

\section{CONCLUSÃO}

Este estudo procurou analisar o reaproveitamento do rejeito de manganês como agregado graúdo e miúdo no concreto para sua utilização na construção civil, apresentando resultados que sugerem ser possível a sua aplicação.

A soma dos teores médios de $\mathrm{SiO}_{2}, \mathrm{Fe}_{2} \mathrm{O}_{3}$ e $\mathrm{Al}_{2} \mathrm{O}_{3}$ encontrados nas amostras de rejeito de $\mathrm{Mn}$ (58,27\%), resultaram em um valor muito baixo para que um determinado material seja considerado pozolânico, por esse motivo utilizou-se como agregado. A difratometria realizada no rejeito de Mn apresentou intensa quantidade de picos em seu difratograma, típicos de fases cristalinas, confirmando a baixa reatividade do material. Com relação a reatividade álcali-agregado, o rejeito de $\mathrm{Mn}$ se classificou como material potencialmente inócuo, possibilitando sua investigação como agregado miúdo.

Ao ponto de vista dos ensaios mecânicos realizados, tendo em média pequenas variações de $1,2 \%$ a longo das primeiras idades, porém, aos 28 dias é perceptível um decréscimo de $18 \%$ na resistência à compressão quando comparado o CRM ao CR. Contudo o uso de superplastificante no adensamento no CRM foi fundamental no alcance do Slump, enquanto o CR não necessitou do uso para um Slump menor de $19 \mathrm{~cm}$.

\section{BIBLIOGRAFIA}

AFONSO, Júlio Carlos. Manganês no Brasil: Descoberta, Extração, Consumo e Comercialização numa Perspectiva Histórica. Revista Química Nova, São Paulo, Vol. 42, n 10, 1172-1183, 04 nov. 2019. Disponível em: http://dx.doi.org/10.21577/01004042.201704435. Acesso em: 17 jan. 2020.

AGÊNCIA VALE. Relatório de Produção: Produção e vendas da Vale no 4T17, 16 fev. 2018. Disponível em: http://vale.com/PT/ investors/information-market/Press-Releases/ReleaseDocuments/2017\%204Q\%20Production\%20Report_p.pdf. Acesso em: 9 fev. 2019.

ASSOCIAÇÃO BRASILEIRA DE NORMAS TÉCNICAS. NBR 7211: Agregados para concreto - Especificação. Rio de Janeiro, 2009. ASSOCIAÇÃO BRASILEIRA DE NORMAS TÉCNICAS. NBR 100007: Amostragem de resíduos sólidos. Rio de Janeiro, 2004. 
ASSOCIAÇÃO BRASILEIRA DE NORMAS TÉCNICAS. NBR 15577-4: Agregados - Reatividade álcali-agregado, Parte 4: Determinação da expansão em barras de argamassa pelo método acelerado. Rio de Janeiro, 2018.

ASSOCIAÇÃO BRASILEIRA DE NORMAS TÉCNICAS. NBR 16697: Cimento Portland - Requisitos. Rio de Janeiro, 2018.

ASSOCIAÇÃO BRASILEIRA DE NORMAS TÉCNICAS. NBR NM 45: Agregados - Determinação da massa unitária e do volume de vazios. Rio de Janeiro, 2006.

ASSOCIAÇÃO BRASILEIRA DE NORMAS TÉCNICAS. NBR NM 52: Agregado miúdo - Determinação da massa específica e massa específica aparente. Rio de Janeiro, 2009.

ASSOCIAÇÃO BRASILEIRA DE NORMAS TÉCNICAS. NBR NM 248: Agregados - Determinação da composição granulométrica. Rio de Janeiro, 2003.

BRASIL. Ministério de Minas e Energia. Produto 11: Minério de manganês, Consultor. Luiz Felipe Quaresma. Projeto de Assistência Técnica ao Setor de Energia. Relatório Técnico 19, Perfil da mineração de manganês, ago. 2009.

CASTRO, C. G. Estudo do Aproveitamento de Rejeitos do Beneficiamento do Manganês pela Indústria Cerâmica, Dissertação de Mestrado, Programa de Pós-Graduação em Engenharia de Materiais da rede Temática. Universidade Federal de Ouro Preto. Ouro Preto, 2011.

$\mathrm{CHOI}, \mathrm{H}$. B..; KIM, J. M. Properties of silicon manganese slag as an aggregate for concrete depending on cooling conditions, Journal of Material Cycles and Waste Management, Vol. 22, p. 1067-1080, 2020.

DRUMMOND, José Augusto; PEREIRA, Mariângela de Araujo P. O Amapá nos tempos do manganês: um estudo sobre o desenvolvimento de um estado amazônico. Rio de Janeiro: Garamond, 2007.

FACUNDES, R. S. Danos Socioambientais Provenientes do Manuseio Inadequado de Rejeitos de Manganês e as Implicações rara a Vida e a Saúde dos Moradores da Vila do Elesbão, Dissertação de Mestrado, Programa de Pós-Graduação em Direito Ambiental e Políticas Públicas. Universidade Federal do Amapá. Macapá, 2011.

FARIA, G. L.; REIS, E. L.; JANOTTI JUNIOR, N.; ARAÚJO, F. G. S. Caracterização química, física e mineralógica do produto granulado de manganês proveniente da Mina do Azul, Revista Matéria, Vol. 17, n 1, p. 901-908, 2012.

HAN, F.; LI, L.; SONG, S.; LIU, J. Early-age hydration characteristics of composite binder containing iron tailing powder, Powder Technology, Vol. 315, p. 322-331, 2017.

HEIDER, Mathias; AMARANTE, José Luiz. Evolução da Produção do Manganês no Brasil. Revista In The Mine, São Paulo, edições 72-73, p. 9-11, julho 2018. Disponível em: http://inthemine.com.br/site/evolucao-da-producao-no-brasil-2/. Acesso em: 8 nov.2018.

JOHN, V. M. Materiais de construção e o meio ambiente. Capítulo de tese editado. 2017. Disponível em: http://ppgec.poli.usp. br/wp-content/uploads/sites/277/2017/05/VMJOHN-Materiais-e-o-meio-ambiente-2017-09-30-1.pdf. Acesso em: 2 dez. 2019.

LI, C.; SUN, H.; YI, Z.; LI, L. Innovative methodology for comprehensive utilization of iron ore tailings, Part 2: The residues after iron recovery from iron ore tailings to prepare cementitious material, Journal of Hazardous Materials, Vol. 174, n 1-3, p. 78-83, 2010.

MELO, Valeria Alves Rodrigues de. Utilização do resíduo gerado na exploração do itabirito em substituição ao agregado miúdo natural para preparação de argamassa de cimento Portland. Dissertação. Programa de Pós-Graduação em Engenharia de Materiais. Universidade Estadual de Minas Gerais. Belo Horizonte, 2012.

MONTEIRO M. A. A ICOMI no Amapá: meio século de exploração mineral, Novos Cadernos NAEA, Vol. 6, n 2, p. 113-168, 2003.

PALANKAR, N.; RAVI SHANKAR, A. U.; MITHUN, B. M. Durability studies on eco-friendly concrete mixes incorporating steel slag as coarse aggregates, Journal of Cleaner Production, Vol. 129, p. 437-448, 2016.

PIMENTEL, M. G.; GOMES, C. F. F.; SILVA, M. R. C.; VIVEIROS, D. S.; PICANÇO, PICANÇO, M. S. Resíduo de minério de Manganês da região amazônica e o seu potencial uso como material suplementar ao cimento Portland. In: XVIII Encontro Nacional de Tecnologia do Ambiente Construído - ENTAC, 18, 2020, Porto Alegre. Anais. Porto Alegre. ANTAC, 2020.

REIS, E. L.; FARIA, G. L.; ARAÚJO, F. G. S.; TENÓRIO, J. A. S.; VIEIRA, C. B.; JANNOTTI JUNIOR, N. Caracterização de uma tipologia de minério de manganês do Brasil, Revista Escola de Minas, Vol. 63, n 3, p. 517-521, 2010.

RIBEIRO, Benjamin Adiron. Vila Serra do Navio, comunidade urbana na selva amazônica: Um projeto do arquiteto Oswaldo Arthur Bratke. São Paulo: Pini, 1992.

SALGUERO; F.; GRANDE, J. A.; VALENTE, T.; GARRIDO, R.; DE LA TORRE M. L.; FORTES, J. C.; SÁNCHEZ, A. Recycling of manganese gangue materials from waste-dumps in the Iberian Pyrite Belt. Application as filler for concrete production, Revista Escola de Minas, Vol. 54, p. 363-368, 2014.

SILVA JUNIOR, P. R. Rejeito de manganês proveniente da Amazônia Oriental em substituição parcial do agregado miúdo natural em concreto, Dissertação de Mestrado, Instituto de Tecnologia, Universidade Federal do Pará. Belém, 2019.

VIVEIROS, D. C. S. Rejeito do minério de manganês como material de construção civil, Dissertação de Mestrado, Instituto de Tecnológia, Universidade Federal do Pará. Belém, 2017. 